\title{
Response
}

\section{Contingent valuation studies and health policy}

\author{
MATTHEW D. ADLER* \\ University of Pennsylvania Law School, Philadelphia, PA, USA
}

I am glad to have the opportunity to respond to the fine paper by Professors Smith and Sach (2009). They raise both foundational questions concerning the justification of contingent valuation studies in the health policy area, and important implementation questions concerning the appropriate design of such studies. I will focus my attention on the question of justification.

The debate about contingent valuation in health policy is part and parcel of the debate between those who favour cost-benefit analysis (CBA), and those who favour cost-effectiveness analysis (CEA) (Adler, 2006: 1-17). CBA values all well-being impacts, including health and longevity, in dollar terms, and aggregates. Technically, CBA evaluates policies by aggregating willingness-to-pay/willingnessto-accept amounts (WTPs). Standard techniques for estimating WTPs are twofold: revealed preference techniques, which estimate them based on market behaviour (such techniques have been widely used to estimate WTPs for fatality risk reduction, known as the 'value of statistical life'); and survey techniques. 'Contingent valuation' is just the technical term for such survey techniques.

CEA, like CBA, values non-health impacts ('costs') in dollar terms; but it values health impacts on some non-monetary 'effectiveness' scale. It then examines the incremental cost-effectiveness ratios of policies in order to determine which policies to adopt. Techniques for estimating WTPs for health impacts - in particular, contingent valuation studies of health effects - therefore have no direct role in CEA.

So one can take a first crack at the question of justification for health care contingent valuation studies by asking, should CBA or CEA be used to evaluate health policies? Now, this question is often seen in the health policy literature as just a choice between 'welfarism' and 'extrawelfarism'. Welfarism favours CBA, extrawelfarism favours CEA - or so it is often assumed.

I think the assumption is doubly mistaken. First - although I cannot pursue the point at length here - I think that CEA should be seen by extrawelfarists as little better than CBA. To adequately develop the point, we would need to get clear about the content of extrawelfarism - a large task (Brouwer et al., 2008).

\footnotetext{
*Correspondence to: Matthew D. Adler, Leon Meltzer Professor, University of Pennsylvania Law School,
} 3400 Chestnut Street, Philadelphia, PA 19104, USA. Email: madler@law.upenn.edu 
Let me just briefly note the following. (1) Extrawelfarism, in the philosophical literature, as in Sen's discussion of 'capabilities', is often associated with the important observation that policy should be concerned about individuals' opportunities, their capability sets, and not their achieved well-being (Arneson, 1989; Sen, 1992). Two individuals with equal opportunities who end up at different levels of well-being because of their own free choices have no claim to government intervention to repair the inequality. However, because CEA, like CBA, focuses on individuals' actual health states - not health opportunities this opportunity-based strain of extrawelfarism in no way argues for CEA over CBA. $^{1}$ (2) Extrawelfarism is also associated with a critique of a preference- or utility-based conception of well-being. But CEA increasingly employs qualityadjusted life years (QALYs) as the measure of 'effectiveness'. And QALYs, of course, calibrate health states on a $0-1$ scale by using standard-gamble, time tradeoff, or rating-scale techniques to elicit individuals' preferences over health states. (3) Finally, extrawelfarism is sometimes linked to a 'deliberative democratic' or 'civic republican' view of policy-making. Policy-making should ultimately be grounded in citizen deliberation. But it is deeply unclear why this premise justifies CEA rather than CBA, at least as a general matter. If citizens are directly deliberating about particular policies, both techniques are superfluous. If citizens have delegated some of their decision-making power to governmental decision-makers (e.g. the administrators of health care agencies), then the question becomes: which technique do citizens want their delegates to employ? In the United States, the answer seems to be CBA. Since 1981, Republican and Democratic Presidents alike, the officials most responsive to the views of the median national citizen, have instructed agencies to employ CBA in evaluating policies (Adler and Posner, 2006). In the United Kingdom, the answer seems to be CEA.

In any event, even if extrawelfarism does generally favour CEA, it is incorrect that welfarism necessarily favours CBA over CEA. This will be the main thrust of my comment. My sense is that many health economists would agree with the following proposition: '[W] hen we accept the methodology of welfare economics, we should use cost-benefit analysis, not cost-effectiveness analysis.' (Kenkel, 1997). But, on examination, the proposition turns out to be very problematic.

What does welfarism involve? At a minimum, welfarism certainly involves the Pareto principle. If individuals are equally well off in outcomes $x$ and $y$, the two outcomes are equally good. And if at least one person is better off in $x$ than $y$, with no one worse off, then $x$ is a better outcome.

Many applied economists, further, adopt the principle of Kaldor-Hicks efficiency, also known as the 'potential Pareto' principle (Just et al., 2004: 1-48). Take outcomes $x$ and $y$. If there is a hypothetical costless lump-sum redistribution in $x$, from those who are better off to those who are worse off, which would make everyone at

1 Indeed, insofar as it can incorporate option values, it may be that CBA can be more sensitive to opportunities than CEA. 
least as well off in $x$ as in $y$ and some strictly better off, then $x$ is a better outcome. If we adopt the Kaldor-Hicks principle as the master principle of welfarism, and if we see CBA as a metric of Kaldor-Hicks efficiency, then it follows that CBA, not CEA, is the best technique for evaluating health policies.

But the Kaldor-Hicks principle is deeply problematic. There is a huge gulf, here, between applied economics, where the principle is often espoused or presupposed, and theoretical economics, where it is often rejected. The flaws of the KaldorHicks principle have been thoroughly canvassed in the theoretical literature (Chipman and Moore, 1978; Boadway and Bruce, 1984: 96-101; Gravel, 2001; Gowdy, 2004). As economists beginning with Scitovsky have noted, it gives rise to various 'reversals' and intransitivities. Further, the principle just conflates potential with actual Pareto superiority. If everyone in $x$ is actually no worse off than in $y$, and at least one individual is better off in $x$, then the Pareto principle itself says $x$ is a better outcome; we don't need to invoke the Kaldor-Hicks principle. And if $x$ is not actually Pareto superior to $y$, how does the fact that $x$ can be hypothetically transformed into a Pareto superior outcome (via an impossible, because costless, redistributive procedure) make $x$ better (Sen, 1979: 23-25)?

In addition, as economists beginning with Boadway have shown, the KaldorHicks principle and CBA are actually not equivalent (Blackorby and Donaldson, 1990).

So what does welfarism involve, if not Kaldor-Hicks efficiency? Many theoretical economists favour the use of social welfare functions (SWFs) to evaluate policy; and some applied work actually does so, particularly applied work in the area of 'optimal tax policy', but also in other areas, for example environmental economics (for an overview and defence of the SWF framework, with citations to the literature, see Adler, 2008: 25-47; see also Adler, 2010). The SWF framework assumes that well-being is interpersonally comparable, and that an individual's well-being can be represented by a utility function. This enables us to represent a given outcome as a vector of utilities; an SWF, in turn, maps each such vector onto a scalar. A better outcome gets a higher number.

SWFs can have various functional forms, but the form that is very often employed in applied work - and one that can be provided a strong axiomatic defence - is the following:

$$
s(x)=\frac{1}{1-\gamma} \sum_{i=1}^{I} u_{i}^{1-\gamma},
$$

where there are $I$ individuals in the population, $u_{i}$ is the utility of individual $i$, and $\gamma$ is an inequality-aversion parameter, which ranges from 0 to infinity. ${ }^{2}$ Where $\gamma$ is zero, the SWF becomes the utilitarian SWF, which simply sums utilities. As $\gamma$ becomes larger, the SWF becomes increasingly concerned about equality. It gives relatively larger weight to utility increments affecting individuals

2 In the special case where $\gamma$ is 1 , the SWF is $\sum \log \left(u_{i}\right)$. 
at lower utility levels, as opposed to utility increments affecting individuals at higher utility levels.

Some health policy scholars have discussed the potential role of SWFs; but their focus tends to be the use of SWFs to rank outcomes understood as vectors of health utilities (see scholarship cited in Adler, 2008: 16, note 51). Since individual well-being is determined not only by individual health, but also by various non-health characteristics (such as consumption, happiness, social status, social life, and other characteristics), we should think of the SWF approach as incorporating a utility function that, ideally, includes both health and non-health characteristics as its arguments.

Taking the SWF framework as the best specification of welfarism, we can see that both CBA and CEA are imperfect measures for evaluating policies - imperfect from the perspective of welfarism. I will illustrate how both CEA and CEA can deviate from the SWF approach using a simple mathematical model. The model employs a standard framework for thinking about the interaction between health and consumption in producing well-being, namely a multiplicative framework, such that $u$, an individual's utility, equals the product of his health utility and consumption utility (Bleichrodt and Quiggin, 1999; Hammitt et al., 2008: note 6). Although it is instructive, I believe, to work through the model, the reader pressed for time can skip ahead 10 paragraphs. The upshot is as follows. Within the model, CBA deviates from CEA, because health benefits realised by individuals at higher consumption levels are adjusted upwards, both because of their higher consumption levels and because their marginal utility of consumption is lower. The SWF approach deviates not only from CEA, but also from CBA. This approach adjusts health benefits to reflect the consumption level of the beneficiary, and to reflect the social benefit of giving welfare improvements to individuals, which varies depending on the well-being level of the individual. Specifically, in the case of individuals who are at higher consumption levels, the SWF approach adjusts health benefits upwards to reflect the higher consumption level of the beneficiary, but also applies a downward adjustment factor to reflect the fact that such individuals are at higher well-being levels.

\section{How CEA, CBA, and SWF diverge: a simple model}

This model assumes that individual well-being is a function of health and consumption. Individuals live for just one period. Individual utility has the form $u=v(c) q(b)$, where $c$ is consumption; $v($.$) is a subutility function valuing con-$ sumption; $h$ is the individual's health state; $q($.$) is a subutility function valuing$ the individual's health; $q$ ranges from zero to one (so is the sort of value that might be measured by standard QALY surveys); $v^{\prime}(c)$ is greater than zero; and $v^{\prime \prime}(c)$ is less than zero.

Let us imagine, now, that a governmental body is choosing between two health programmes, $\mathrm{P}^{*}$ and $\mathrm{P}^{+}$. Each programme would produce health gains for 
a homogenous subpopulation of $N$ individuals. Neither would displace an existing programme. Each programme would also produce costs, in the form of lost consumption. For simplicity, assume that the $M$ individuals who would bear the consumption costs of either policy are distinct from the individuals who would receive their health benefits; that the two policies would produce the very same pattern of lost consumption for the $M$ individuals; and that the governmental body is required by statute to choose either $\mathrm{P}^{*}$ or $\mathrm{P}^{+}$(so, for simplicity, we can ignore the option of choosing neither).

The individuals who would benefit from $\mathrm{P}^{*}$ are currently at consumption level $c^{*}$, and the $q$-value of their current health state is $q^{*}$. The individuals who would benefit from $\mathrm{P}^{+}$are currently at consumption level $c^{+}$, and the $q$-value of their current health state is $q^{+} . \mathrm{P}^{*}$ and $\mathrm{P}^{+}$each would produce the very same change in health utility, $\Delta q$ : $\mathrm{P}^{*}$ would improve the $q$-value of each beneficiary's health from $q^{*}$ to $q^{*}+\Delta q$, while $\mathrm{P}^{+}$would improve the $q$-value of each beneficiary's health from $q^{+}$to $q^{+}+\Delta q$.

Given these simplifying assumptions (including the crucial assumption that the policies produce the very same pattern of lost consumption for the $M$ costbearers, and that the agency must choose $\mathrm{P}^{*}$ or $\mathrm{P}^{+}$), the three policy techniques on the table - CEA, CBA, and the SWF framework - all make the choice by, in effect, assigning the individual health benefit of each policy a social value, $\Delta b^{*}$ or $\Delta b^{+}$, and choosing the policy with the larger $N \Delta b$ value. However, CEA, CBA, and the SWF approach differ in how they calculate $\Delta b$.

Assuming that CEA uses the $q$-value of each programme as its measure of effectiveness, $\Delta b=\Delta q$. The total social benefits of $\mathrm{P}^{*}$ are $N \Delta q^{*}$, while the total social benefits of $\mathrm{P}^{+}$are $N \Delta q^{+}$, which are equal because $\Delta q^{*}=\Delta q^{+}=\Delta q$. Both programmes produce the very same total health benefit, and so CEA views them as equally good.

For CBA, $\Delta b$ is the individual's WTP for the programme. Call this $\Delta c$, defined as follows: $v(c-\Delta c)(q+\Delta q)=v(c) q$. Assuming $\Delta q$ is small, this can be approximated as follows:

$$
\Delta c \approx \frac{v(c)}{v^{\prime}(c)} \frac{\Delta q}{q+\Delta q}
$$

Finally, if we use an SWF of the form $s=\frac{1}{1-\gamma} \sum_{i=1}^{I} u_{i}^{1-\gamma}, \Delta b$ equals $\frac{1}{1-\gamma}(u+\Delta u)^{1-\gamma}-\frac{1}{1-\gamma} u^{1-y}$, where $u$ is the initial utility of each programme beneficiary and $\Delta u$ the change in her utility from the programme. Assuming $\Delta q$ is small, this can be approximated as follows. ${ }^{3}$

$$
\frac{1}{1-\gamma}\left[(u+\Delta u)^{1-\gamma}-u^{1-\gamma}\right] \approx u^{-\gamma} \Delta q v(c)=\Delta q v(c)[v(c) q]^{-\gamma}
$$

The following table summarises how CEA, CBA, and the SWF approach calculate the total social benefit, $N \Delta b$ of each programme.

3 If we define $g(u)$ as $\frac{1}{1-\gamma} u^{1-\gamma}$, then $g(u+\Delta u)-g(u) \approx g^{\prime}(u) \Delta u$ for small $\Delta u$. Note that $g^{\prime}(u)=u^{-\gamma}$. $\Delta u$, in turn, equals $\Delta q v(c)$. 
Three ways to calculate the social benefits of health programmes

\begin{tabular}{lll}
\hline \hline & Programme $\mathrm{P}^{*}$ & Programme $\mathrm{P}^{+}$ \\
\hline CEA & $N \Delta \mathrm{q}$ & $N \Delta \mathrm{q}$ \\
$\mathrm{CBA}$ & $N \Delta q \frac{v\left(c^{*}\right)}{v^{\prime}\left(c^{*}\right)\left(q^{*}+\Delta q\right)}$ & $N \Delta q \frac{v\left(c^{+}\right)}{v^{\prime}\left(c^{+}\right)\left(q^{+}+\Delta q\right)}$ \\
$\mathrm{SWF}$ & $N \Delta q v\left(c^{*}\right)\left(q^{*} v\left(c^{*}\right)\right)^{-\gamma}$ & $N \Delta q v\left(c^{+}\right)\left(q^{+} v\left(c^{+}\right)\right)^{-\gamma}$ \\
\hline \hline
\end{tabular}

In contrast with CEA, which sets $\Delta b=\Delta q, \mathrm{CBA}$ and the SWF approach calculate $\Delta b$ (for small $\Delta q$ ) by multiplying $\Delta q$ with various scaling factors. In the case of CBA, there are two such factors: $v(c)$, and a second factor, $\left(v^{\prime}(c)(q+\right.$ $\Delta q))^{-1}$, which is approximately equal to the inverse of the marginal utility of consumption, $\partial u / \partial c$. Note that both of these factors are increasing in $c$. In the case of the SWF approach, there are also two factors, $v(c)$ and a second factor, $(q v(c))^{-\gamma}$. This second factor is the marginal effect on the SWF of a change in some individual's utility, that is, $d s / d u$. Note that this second factor is decreasing in $c$ if $\gamma>0$ and the SWF is inequality-averse. As individual consumption increases, the individual's utility level increases; and so the social value of an increment in her utility decreases, given an inequality-averse SWF.

To see how CEA, CBA, and the SWF approach diverge not just in calculating benefits but in their bottom-line choice of programmes, imagine that $q^{*}=q^{+}$, and $c^{*}>c^{+}$. CEA is always indifferent between the programmes, including in this case. In this case, CBA chooses $\mathrm{P}^{*}$ : its beneficiaries have a higher consumption level and a lower marginal utility of consumption, both of which produce a higher WTP than for the beneficiaries of $\mathrm{P}^{+}$. Finally, the utilitarian SWF also chooses $\mathrm{P}^{*}$, because the utility change from that programme $\left(\Delta q v\left(c^{*}\right)\right)$ is greater than the utility change from the other programme $\left(\left(\Delta q v\left(c^{+}\right)\right)\right.$. However, if $\gamma$ is sufficiently large, and the SWF sufficiently inequality-averse, it will choose $\mathrm{P}^{+} .4$ Because those who would benefit from the $\mathrm{P}^{+}$programme have a lower utility level than those who would benefit from the $\mathrm{P}^{*}$ programme, a sufficiently inequality-averse SWF will choose to give a smaller utility benefit $\left(\Delta q v\left(c^{+}\right)\right)$to them, over a larger utility benefit $\left(\Delta q v\left(c^{*}\right)\right)$ to the $\mathrm{P}^{*}$ beneficiaries.

In short, CBA and CEA can deviate from each other - which is well known in the health economics literature (Dolan and Edlin, 2002). However, each can also deviate from what is very plausibly the best specification of welfarism, the SWF approach - a point not sufficiently emphasised in that literature.

With these observations in hand, let us return to the question: What should be the role of contingent valuation studies in health policy choice, given welfarism? One possibility is that we use SWFs rather than CBA or CEA to guide health policy.

4 More precisely, if $\gamma>1$, the SWF approach chooses $\mathrm{P}^{+}$. 
This is currently unlikely, for various reasons. One is professional culture and training. As mentioned, SWFs do have currency in some areas of economics; but both CEA and CBA are much more widespread in governmental practice and in policy-analysis scholarship. Another difficulty for the SWF approach is that we currently lack good survey research focused on calibrating individual utility as a function of health, consumption, and other determinants of well-being. Contingent valuation studies can actually be very useful in this calibration exercise (Viscusi and Evans, 1990; Evans and Viscusi, 1991; Sloan et al., 1998). Currently, however, they are generally used to estimate WTP amounts, not to calibrate the utility function.

A second, more likely possibility is that we continue to use CBA or CEA or both to evaluate health policy. I have argued elsewhere that CBA and CEA, under appropriate conditions, can each be seen as rough proxies for a utilitarian SWF - for the maximisation of overall well-being (Adler, 2006; Adler and Posner, 2006). ${ }^{5}$ In this world, the current world, contingent valuation studies have a very important role to play, as one source for estimating WTP amounts.

A third, intermediate possibility is that we use the SWF framework to adjust CBA or CEA. The possibility of adjusting CBA with distributive weights, to correct for heterogeneity in the marginal utility of income/consumption, or to take account of social inequality-aversion, has been discussed by economists (Johansson-Stenman, 2005). I have argued in prior work that we might perform CBA using multiple monetary measures of health benefits: not just WTP amounts, but amounts produced by multiplying QALY amounts by a QALY-todollar conversion factor, the optimum value of which can be set with reference to a utilitarian (or perhaps even non-utilitarian) SWF (Adler, 2006). A very similar thought is that the proponent of CEA might use SWFs to optimise the cutoff cost-effectiveness ratios that CEA sometimes employs.

In this, intermediate, world, contingent valuation studies function both as estimates of WTPs, and as a basis for calibrating the individual utility function.

To sum up: contingent valuation research has a vital role in health policy choice, at least given welfarism - but not in the service of Kaldor-Hicks efficiency. ${ }^{6}$

5 This can be seen from the simple example above. CBA is a good proxy for the utilitarian SWF, where the marginal utility of income/consumption does not vary too much among the individuals affected by the policy choice. In the simple example, note that, if $\gamma$ is zero, the SWF approach calculates $\Delta b$ as $\Delta q v(c)$. CBA calculates $\Delta b$ as approximately $\Delta q v(c)(\partial u / \partial c)^{-1}$, which leads to the same ranking of the programs if $\partial u / \partial c$ is the same for the beneficiaries of $\mathrm{P}^{*}$ and $\mathrm{P}^{+}$.

CEA is a good proxy for the utilitarian SWF where individuals are homogenous with respect to their non-health characteristics. In the simple example, note that, if $\gamma$ is zero, the SWF approach calculates $\Delta b$ as $\Delta q v(c)$. CEA calculates $\Delta b$ as $\Delta q$. If the beneficiaries of both programs have the same consumption level, the SWF approach and CEA therefore rank the policies the same way (each approach being indifferent between the policies).

6 A sophisticated defense of using Kaldor-Hicks efficiency to evaluate non-tax policies, including health policies, points to the possibility of redistribution through the tax system - not just an ideal system of lump sum taxes, but the distortionary income tax (Kaplow and Shavell, 1994). However, this defense turns out to be problematic (Sanchirico, 2001; Johansson-Stenman, 2005). 
Rather, contingent valuation research should function to estimate the inputs to CBA (WTP amounts), with CBA understood as a rough proxy for overall well-being; and to help us estimate the individual utility function, as a function of both health and non-health characteristics, so that we improve the performance of CBA and CEA and ultimately, perhaps, move beyond these frameworks entirely and use a more theoretically attractive tool, the SWF.

How do my views on these matters differ from Professors Smith and Sach's? Of course, there is one very large difference: I emphasise the SWF perspective, while they do not. We also seem to disagree, somewhat, about the use of contingent valuation studies to estimate WTP amounts. They emphasise the importance of focusing such studies on non-use values, that is, process values, option values, and caring externalities; while it seems to me that contingent valuation studies can be very helpful in estimating WTP amounts (and, for that matter, in calibrating a utility function) even if focused just on health. But this is a quibble. What we do share is a willingness to challenge the conventional wisdom that contingent valuation studies are useful only as a tool to implement traditional CBA, the unweighted sum of WTP amounts, and only by virtue of a core commitment to Kaldor-Hicks efficiency.

\section{Acknowledgements}

I would like to thank Paul Dolan, Kristin Madison, and Lisa Robinson for their helpful comments.

\section{References}

Adler, M. D. (2006), 'QALYs and policy evaluation: a new perspective', Yale Journal of Health Policy, Law, and Ethics, 6: 1-92.

Adler, M. D. (2008), 'Risk equity: a new proposal', Harvard Environmental Law Review, 32: $1-47$.

Adler, M. D. (2010), Well-being and Equity: A Framework for Policy Analysis, Oxford: Oxford University Press (in press).

Adler, M. D. and E. A. Posner (2006), New Foundations of Cost-Benefit Analysis, Cambridge, MA: Harvard University Press.

Arneson, R. J. (1989), 'Equality and equal opportunity for welfare', Philosophical Studies, 56: 77-93.

Blackorby, C. and D. Donaldson (1990), 'A review article: the case against the use of the sum of compensating variations in cost-benefit analysis', Canadian Journal of Economics, 23: 471-494.

Bleichrodt, H. and J. Quiggin (1999), 'Life cycle preferences over consumption and health: when is cost-effectiveness analysis equivalent to cost-benefit analysis?', Journal of Health Economics, 18: 681-708.

Boadway, R. and N. Bruce (1984), Welfare Economics, Oxford: Blackwell.

Brouwer, W. B. F., A. J. Culyer, N. J. A. van Exel and F. F. H. Rutten (2008), 'Welfarism vs. extra-welfarism', Journal of Health Economics, 27: 325-338. 
Chipman, J. S. and J. C. Moore (1978), 'The new welfare economics 1939-1974', International Economic Review, 19: 547-584.

Dolan, P. and R. Edlin (2002), 'Is it really possible to build a bridge between cost-benefit analysis and cost-effectiveness analysis?', Journal of Health Economics, 21: 827-843.

Evans, W. N. and W. K. Viscusi (1991), 'Estimation of state-dependent utility functions using survey data', Review of Economics and Statistics, 73: 94-104.

Gowdy, J. M. (2004), 'The revolution in welfare economics and its implications for environmental valuation and policy', Land Economics, 80: 239-257.

Gravel, N. (2001), 'On the difficulty of combining actual and potential criteria for an increase in social welfare', Economic Theory, 17: 163-180.

Hammitt, J. K., K. Haninger and N. Treich (2008), 'Effects of health and longevity on financial risk tolerance', Working Paper.

Johansson-Stenman, O. (2005), 'Distributional weights in cost-benefit analysis: should we forget about them?', Land Economics, 81: 337-352.

Just, R. E., D. L. Hueth and A. Schmitz (2004), The Welfare Economics of Public Policy: A Practical Approach to Project and Policy Evaluation, Northampton, MA: Edward Elgar.

Kaplow, L. and S. Shavell (1994), 'Why the legal system is less efficient than the income tax in redistributing income', Journal of Legal Studies, 23: 667-681.

Kenkel, D. (1997), 'On valuing morbidity, cost-effectiveness, and being rude', Journal of Health Economics, 16: 749-757.

Sanchirico, C. W. (2001), 'Deconstructing the new efficiency rationale', Cornell Law Review, 86: 1003-1089.

Sen, A. (1979), 'The welfare basis of real income comparisons: a survey', Journal of Economic Literature, 17: 1-45.

Sen, A. (1992), Inequality Reexamined, Cambridge, MA: Harvard University Press.

Sloan, F. A., W. K. Viscusi, H. W. Chesson, C. J. Conover and K. Whetten-Goldstein (1998), 'Alternative approaches to valuing intangible health losses: the evidence for multiple sclerosis', Journal of Health Economics, 17: 475-497.

Smith, R. D. and T. H. Sach (2009), 'Contingent valuation: what needs to be done?', Health Economics, Policy and Law (in press). doi:10.1017/S174413310999016

Viscusi, W. K. and W. N. Evans (1990), 'Utility functions that depend on health status: Estimates and economic implications', American Economic Review, 80: 353-374. 